\title{
Análise não destrutiva de pigmentos fotossintéticos em folhas de gergelim
}

\author{
João P. G. Rigon ${ }^{1}$, N apoleão E. de M. Beltrão ${ }^{2}$, Silvia Capuani ${ }^{1}$, \\ Jósé F. de Brito $\mathrm{Neto}^{2} \&$ Fabíola V. de F. Silva ${ }^{3}$
}

\begin{abstract}
RESU M O
O bjetivou-se, com o presente trabalho, relacionar pigmentos fotossintéticos extraídos de modo clássico em laboratório com leituras obtidas pelo clorofilômetro portátil ClorofiLO G 1030, em folhas de gergelim, por meio de modelos matemáticos. 0 trabalho foi realizado em dezembro de 2010, na Embrapa Algodão, de onde foram retirados discos foliares de gergelim para serem mensurados os índices de clorofila por meio do clorofilômetro portátil. $\mathrm{O} s$ discos foliares foram submetidos à extração dos pigmentos fotossintéticos, utilizando-se $5 \mathrm{~mL}$ de dimetilsulfóxido (DMSO) e mantidos em banho-maria a $70{ }^{\circ} \mathrm{C}$, durante $30 \mathrm{~min}$; depois foram retirados $3 \mathrm{~mL}$ de alíquota para a leitura em espectrofotômetro nos comprimentos de onda de 470,646 e $663 \mathrm{~nm}$. Com base nos resultados analíticos modelos matemáticos foram ajustados utilizando-se o índice de clorofila na predição dos teores de clorofila $a$, b e total e dos carotenóides e suas relações. Concluiu-se que o medidor portátil de clorofila ClorofiLOG 1030 pode ser utilizado na estimativa da concentração dos pigmentos fotossintéticos em folhas de gergelim com alta precisão, além de proporcionar economia de recursos e tempo.
\end{abstract}

Palavras-chave: clorofilômetro, clorofila, calibração

\section{Non destructive analysis of photosynthetic pigments in leaves of Sesamum indicum (L.)}

\begin{abstract}
The study aimed to relate the photosynthetic pigments, which were extracted in a laboratory and the readings were obtained by the portable chlorophyll meter ClorofiLOG 1030, by using mathematical models in sesame leaves. This work was conducted in December 2010, at Embrapa Cotton, where feaf discs were removed to measure chlorophyll indexes through the portable chlorophyll meter. The same leaf discs were subjected to extraction of photosynthetic pigments, by using $5 \mathrm{~mL}$ dimethyl sulfoxide (D MSO ), and were kept in a water bath at 70 으 for $30 \mathrm{~min}$. Afterwards, an aliquot of $3 \mathrm{~mL}$ was removed to be read in a spectrophotometer at wavelengths of 470,646 and $663 \mathrm{~nm}$. Based on analytical results, mathematical models were adjusted by using the chlorophyll index to predict the levels of chlorophyll a, $\mathrm{b}$, and total, and of carotenoids and their relationships. The study concluded that the portable chlorophyll meter ClorofiLO 1030 can be used to estimate the concentration of photosynthetic pigments in sesame leaves with high precision, besides saving resources and time.
\end{abstract}

Key words: chlorophyll meter, chlorophyll, calibration

\footnotetext{
${ }^{1}$ M estrandos em Agricultura U niversidade Estadual Paulista Júlio de Mesquita Filho, Faculdade de Ciências Agronômicas, U N ESP/FCA. Rua José Barbosa de Barros, n 1780, Fazenda Lageado, CEP 18610-337, Botucatu, SP. E-mail: jprigon@fca.unesp.br; silviacapuani@fca.unesp.br 2 Embrapa Algodão, CEP 58428-095, Campina Grande, PB. E-mail: napoleao@cnpa.embrapa.br; felix@cnpa.embrapa.br ${ }^{3}$ Centro de Ciências Agrárias/U FPB, Areia-PB, E-mail: favanessa@ig.com.br
} 


\section{INTRODUÇÃO}

A eficiência fotossintética está relacionada ao desenvolvimento das plantas em diferentes ambientes podendo, ao ser determinada, servir de suporte na tomada de decisões, principalmente sobre a adubação nitrogenada (Engel \& Poggiani, 1991). Isto se deve ao fato de a clorofila apresentar alta relação com o rendimento para inúmeras culturas (Smeal \& Zhang, 1994).

A taxa fotossintética pode ser reduzida com a diminuição da concentração do nitrogênio nos vegetais, visto que este altera a resistência estomática na difusão do dióxido de carbono modificando, assim, a atividade da enzima Rubisco, o que significa diminuição da fotossíntese (Costa et al., 1988). Desta forma, existe uma interdependência entre esse nutriente e as plantas, também por estar ligado à clorofila pela conversão da radiação luminosa em energia de ATP e NADPH, que são dependentes de compostos protéicos associados aos cloroplastos (Larcher, 2006).

A metodologia clássica para mensuração dos pigmentos clorofilianos é resultante da coleta destrutiva do vegetal, além de compreender uma prática onerosa. Diferentemente, os leitores portáteis de clorofila utilizam princípios não destrutivos, simples e instantâneos, possibilitando estudos ontogênicos foliares das culturas (Argenta et al., 2001; Richardson et al., 2002; Berg \& Perkins, 2004; Netto et al., 2005; Salla et al., 2007). A determinação indireta do teor relativo de clorofila é calculada pela quantidade de luz transmitida pela folha, por meio de dois ou três comprimentos de onda com diferentes absorbâncias que, independente do instrumento utilizado, fornecem uma leitura única proporcional às clorofilas a e b e aos carotenóides (Minolta Camera Co.). De acordo com Markwell et al. (1995), o clorofilômetro SPAD Minolta utiliza dois diodos emissores de luz nas faixas de 650 e $940 \mathrm{~nm}$ enquanto o ClorofiLOG1030 opera em 635, 660 e $850 \mathrm{~nm}$.

Os modelos que descrevem a relação entre as leituras dos equipamentos portáteis variam para cada cultura, de acordo com as características intrínsecas a cada espécie, exigindo calibração independente (Lee, 1988; Markwell et al., 1995; Uddling et al., 2007). Assim, é importante para a cultura do gergelim que seja realizada a calibração do clorofilômetro portátil; além disso, a literatura não reporta as concentrações de pigmentos fotossintéticos para esta cultura até o momento, razão por que se objetivou, com este trabalho, estabelecer uma relação entre a leitura do índice de clorofila realizada pelo equipamento portátil e a determinação clássica para os pigmentos fotossintéticos na cultura do gergelim, por meio de modelos matemáticos.

\section{Material e MÉTODOS}

Folhas da cultivar BRS Seda, submetidas previamente a diferentes doses de nitrogênio, foram utilizadas para a mensuração dos pigmentos fotossintéticos por meio do equipamento portátil, estabelecendo uma relação com a metodologia clássica de obtenção. O experimento foi conduzido no Centro Nacional de Pesquisa do Algodão, no Laboratório de Fisiologia Vegetal, localizado em Campina Grande, PB, com clima predominante do tipo 'As', quente e úmido.

Com vista à obtenção das análises, amostras de discos foliares com área de $113 \mathrm{~mm}^{2}$ foram coletadas em diferentes estádios de desenvolvimento, com o auxílio de um cilindro de metal vazado; em seguida, o teor relativo de clorofila foi aferido individualmente pelo medidor portátil ClorofiLOG1030 ${ }^{\circledR}$. Os discos foram, então, alocados em tubos de ensaio, envolvidos em papel alumínio para proteção contra a radiação solar e em seguida colocados em uma caixa refrigerada para reduzir a desnaturação das enzimas e proteínas. Seguiu-se a metodologia descrita por Arnon (1949) e adaptada por Hiscox \& Israelstam (1979) para a dissolução das amostras, utilizando-se $5 \mathrm{~mL}$ do reagente dimetilsulfóxido (DMSO) e incubação a $70^{\circ} \mathrm{C}$ por 30 min, em banho-maria, o que foi seguido de agitação individual, a cada $10 \mathrm{~min}$. O equipamento utilizado para as leituras dos pigmentos foi o espectrofotômetro da marca Biomate ${ }^{\circledR \mathrm{tm} 3}$, por meio dos comprimentos de onda de 470, 656 e $663 \mathrm{~nm}$, os quais foram aferidos conforme transferência de uma alíquota para uma cubeta de quartzo com volume de $3 \mathrm{~cm}^{3}$.

Os valores para cada comprimento de onda foram utilizados nas equações relatadas por Wellburn (1994), em $\mu \mathrm{g} \mathrm{mL} \mathrm{m}^{-1}$ de extrato, considerando-se o volume do extrator, a área foliar total extraída e a massa molar das clorofilas a e b e dos carotenóides (Ritchie, 2008). Os teores foram expressos em $\mu \mathrm{mol} \mathrm{m} \mathrm{m}^{-2}$ de lâmina foliar. Os dados individuais foram transformados para cada pigmento analisado e submetidos a análise de regressão, utilizando-se o índice relativo de clorofila como variável dependente, e aos pigmentos fotossintéticos como independentes. Os ajustes das curvas foram realizados pelas funções linear e quadrática, conforme coeficiente de determinação, por meio do programa Sigmaplot ${ }^{\circledR}$ 11.2.

\section{RESULTADOS E DISCUSSÃO}

Ao correlacionar os resultados do clorofilômetro nas folhas de gergelim ao teor de clorofila a $\mu \mathrm{mol} \mathrm{m} \mathrm{m}^{2}$, obtido em laboratório, observa-se que houve alta relação entre as leituras, com coeficiente de determinação de 0,98, conforme a Figura 1A. Evidencia-se que as leituras com o equipamento portátil estimam com ótima precisão os valores desse pigmento fotossintético na cultura do gergelim. Desta forma, o modelo matemático gerado na Figura 1A poderá ser utilizado para estimar o teor de clorofila a em folhas de gergelim. Markwell et al. (1995) também verificaram alta relação entre leituras com o clorofilômetro e a clorofila extraída em laboratório tanto para milho como para a soja, tal como verificaram Netto et al. (2005) em cafeeiro.

A mensuração do conteúdo de clorofila $b$ por meio dos equipamentos portáteis é mais dificultosa quando comparada à leitura da clorofila a, como reportam Richardson et al. (2002) e Neves et al. (2005). Isto ocorre devido ao fato de o comprimento de onda emitido pelo aparelho aproximar-se mais ao pico de absorção da clorofila a, do que ao pigmento b. Verificou-se, no entanto, alta eficiência nas leituras do clorofilômetro em relação às análises laboratoriais para esse pigmento, com coeficientes de determinação de $92 \%$, 

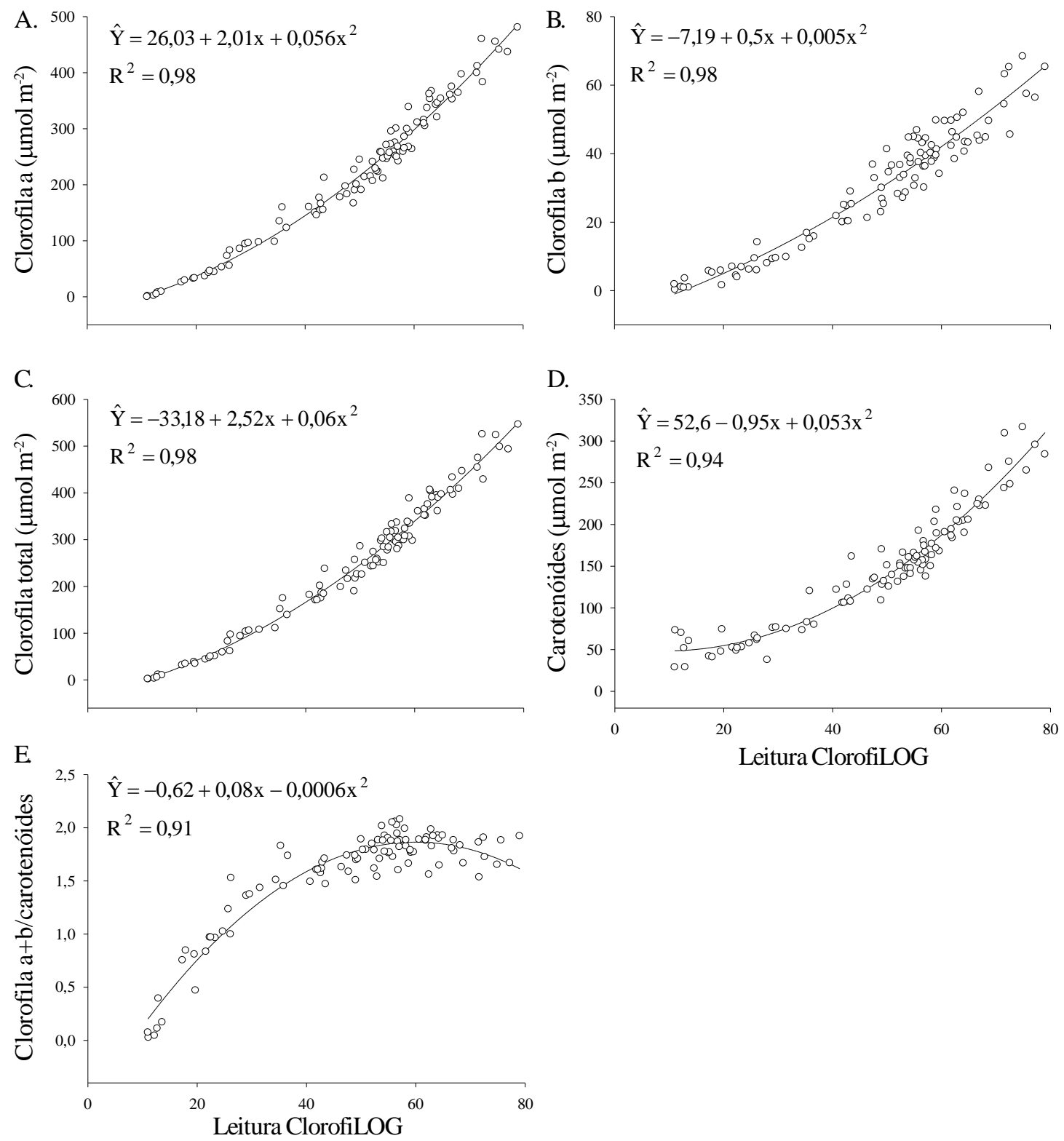

Leitura ClorofiLOG

Figura 1. Relações entre leituras no clorofilômetro portátil ClorofiLOG ${ }^{\circledR}$ e teores de clorofila a (A), clorofila b (B), carotenóides (C), clorofila total (D ) e clorofila a+ b/carotenóides (E) em folhas de gergelim

demonstrando que o equipamento propiciou bom ajuste com o modelo quadrático, conforme a Figura 1B. Da mesma forma, Amarante et al. (2008), encontraram, em folhas de diferentes cultivares de macieira, valores de determinação maiores para a clorofila a que para a b.

Apesar de os valores referentes à clorofila total oscilarem desde zero a $600 \mathrm{mmol} \mathrm{m}^{-2}$ de lâmina foliar, tornou-se possível, também, por meio do equipamento portátil, ajustá-los a um modelo matemático, com alta significância em relação à extração em laboratório, com coeficiente de 0,98, conforme a Figura 1C. Os dados corroboram os de Argenta et al. (2001); Barbieri Júnior et al. (2010) e Brito et al. (2011) que também observaram altos coeficientes de correlação de 0,$98 ; 0,93$ e 0,90 na cultura do milho, do capim tifton e do algodão, respectivamente. Zotarelli et al. (2003) averiguaram, na cultura do milho, coeficientes lineares utilizando o clorofilômetro SPAD, com alta significância.
A relação entre carotenoides e os valores do índice ClorofiLOG em folhas de gergelim são apresentados na Figura 1D. Assim como para os demais pigmentos fotossintéticos, o modelo matemático quadrático foi o que melhor expressou a relação entre a leitura ClorofiLOG ${ }^{\circledR}$ e a concentração de carotenoides no tecido foliar do gergelim, com coeficiente de determinação de 0,94 .

A mensuração dos teores de carotenóides nas folhas é relevante devido ao fato de o excesso energético provocado pela luz interceptada pelo dossel vegetal ser dissipado por esses pigmentos no PS II, onde atuam como fotoprotetores, no caso de sobrecarga energética (Taiz \& Zeiger, 2009). A proporção entre clorofilas e carotenóides é alterada conforme os vegetais sejam submetidos a algum estresse (Young \& Britton, 1990).

Foi possível estabelecer uma relação entre clorofilas e carotenóides por meio das leituras do clorofilômetro portátil 
ClorofiLOG ${ }^{\circledR}$, com alto coeficiente de determinação, conforme a Figura 1E. Segundo Taiz \& Zeiger (2009), as relações com as clorofilas servem como diagnose foliar para proteção fotoxidativa na senescência foliar, servindo como parâmetro de ambiência para o vegetal (Hendry \& Price, 1993; Duarte, 2003).

\section{Conclusões}

1. As leituras ClorofiLOG ${ }^{\circledR}$ se correlacionam com boa precisão com pigmentos fotossintetizantes obtidos pela espectrofotometria em folhas de gergelim.

2. É possível a determinação de compostos fotossintetizantes, por meio do uso do clorofilômetro portátil e de modelos matemáticos ajustados, com economia de tempo e reagentes.

\section{LiTERATURA CITADA}

Amarante, C. V. T. do; Steffens, C. A.; Zanardi, O. Z.; Alves, E. de O. Quantificação de clorofilas em folhas de macieiras 'Royal Gala' e 'Fugi' com métodos ópticos não-destrutivos. Revista Brasileira de Fruticultura, v.30, p.590-595, 2008.

Argenta, G.; Silva, P. R. F. da; Bortolini, C. G.; Forsthofer, E. L.; Striede, M. L. Relação da leitura do clorofilômetro com os teores de clorofila extraível e de nitrogênio na folha de milho. Revista Brasileira de Fisiologia Vegetal, v.13, p.158-167, 2001.

Arnon, D. I. Copper enzymes in isolated chloroplasts: polyphenoloxydase in Beta vulgaris. Plant Physiology, v.24, p.1-15, 1949.

Barbieri Júnior, E.; Rossiello, R. O. P.; Morenz, M. J. F.; Ribeiro, R. C. Comparação de métodos diretos de extração e quantificação dos teores de clorofilas em folhas do capimtifton 85. Ciência Rural, v.40, p.633-636, 2010.

Berg, A. K. van der; Perkins, T. D. Evaluation of a portable chlorophyll meter to estimate chlorophyll and nitrogen contents in sugar maple (Acer saccharum Marsh.) leaves. Forest Ecology and Management, v.200, p.113-117, 2004.

Brito, G. G.; Brandão, Z. N.; Silva, V. B.; Franklin, M. S.; Silva, D. A. Non-destructive analysis of photosynthetic pigments in cotton plants. Acta Scientiarum. Agronomy, v.33, p.671-678, 2011.

Costa, R. C. L. da; Lopes, N. F.; Oliva, M. A.; Barros, N. F. de. Efeito da água e do nitrogênio sobre a fotossíntese, respiração e resistência estomática em Phaseolus vulgaris. Pesquisa Agropecuária Brasileira, v.23, p.1371-1379, 1988.

Duarte, C. C. Detecção óptica da eficiência quântica da fotossíntese. Recife: UFPE. 2003. 109p. Dissertação Mestrado

Engel, V. L.; Poggiani, F. Estudo da concentração de clorofila nas folhas e seu espectro de absorção de luz em função do sombreamento em mudas de quatro espécies florestais nativas. Revista Brasileira de Fisiologia Vegetal, v.3, p.3945, 1991.
Hendry, G. A. F.; Price, A. H. Stress indications: chlorophylls and carotenoids. In: Methods in comparative plant ecology, London: Chapman \& Hall. 1993. p.148-152.

Hiscox, J. D.; Israelstam, G. F. A method for the extraction of chlorophyll from leaf tissue without maceration. Canadian Journal of Botany, v.57, p.1332-1334, 1979.

Larcher, W. Ecofisiologia vegetal. São Paulo: Rimas Artes, 2006. $531 \mathrm{p}$.

Lee, D. W. Simulating forest shade to study the development ecology of tropical plants: Juvenile growth in three vines in India. Journal of Tropical Ecology, v.4, p.281-292, 1988.

Markwell, J.; Osterman, J. C.; Mitchell, J. L. Calibration of the Minolta SPAD-502 leaf chlorophyll meter. Photosynthesis Research, v.46, p.467- 472, 1995.

Netto, A. T.; Campostrini, E.; Oliveira, J. G.; Smith, R. E. B. Photosynthetic pigments, nitrogen, chlorophyll a fluorescence and SPAD-502 readings in coffee leaves. Scientia Horticulturae, v.104, p. 199-209, 2005.

Neves, O. S. C.; Carvalho, J. G. de.; Martins, F. A. D.; Pádua, T. R. P; Pinho, P. J. de. Uso do SPAD-502 na avaliação dos teores foliares de clorofila, nitrogênio, enxofre, ferro e manganês do algodoeiro herbáceo. Pesquisa Agropecuária Brasileira, v.40, p.517-521, 2005.

Richardson, A. D.; Duigan, S. P.; Berlyn, G. P. An evaluation of noninvasive methods to estimate foliar chlorophyll content. New Phytologist, v.153, p.185-194, 2002.

Ritchie, R. J. Universal chlorophyll equations for estimating chlorophylls a, b, c, and d and total chlorophylls in natural assemblages of photosynthetic organisms using acetone, methanol, or ethanol solvents. Photosynthetica, v.46, p.115126, 2008.

Salla, L.; Rodrigues, J. C.; Marenos, R. A. Teores de clorofila em árvores tropicais determinados com SPAD-502. Revista Brasileira de Biociências, v.5, p.59-161, 2007.

Smeal, D.; Zhang, H. Chlorophyll meter evaluation for nitrogen management in corn. Communications in Soil Science and Plant Analysis, v.25, p.1495-1503, 1994.

Taiz, L.; Zeiger, E. Fisiologia vegetal. 4.ed. Porto Alegre: Artmed, 2009. 819p.

Uddling, J.; Gelang-Alfredsson, J.; Piikki, K.; Pleuel, H. Evaluating the relationship between leaf chlorophyll concentration and SPAD-502 chlorophyll meter readings. Journal Photosynthesis Research, v.91, p.37-46, 2007.

Wellburn, A. R. The spectral determination of chlorophylls a and $b$, as weel as total carotenoids, using various solvents with spectrophotometers of different resolution. Journal of Plant Physiology, v.144, p.307-313, 1994.

Young, A.; Britton, G. Carotenoids and stress. In: Alscher, R. G., Cummings, J. R. Stress responses in plants: Adaptation and acclimation mechanisms. New York: Wiley-Liss, 1990, p.87-112.

Zotarelli, L.; Cardoso, E. G.; Piccinin, J. L.; Urquiaga, S.; Boddey, R. M.; Torres, E.; Alves, B. J. R. Calibração do medidor de clorofila Minolta SPAD-502 para avaliação do conteúdo de nitrogênio no milho. Pesquisa Agropecuária Brasileira, v.38, p.1117-1122, 2003. 